\title{
Improving psychotropic drug prescription in nursing home patients with dementia: design of a cluster randomized controlled trial
}

\author{
Claudia HW Smeets ${ }^{1 *}$, Martin Smalbrugge ${ }^{2}$, Debby L Gerritsen ${ }^{1}$, Marjorie HJMG Nelissen-Vrancken ${ }^{3}$, \\ Roland B Wetzels ${ }^{1}$, Klaas van der Spek ${ }^{1}$, Sytse U Zuidema ${ }^{4}$ and Raymond TCM Koopmans ${ }^{1}$
}

\begin{abstract}
Background: Neuropsychiatric symptoms are highly prevalent in nursing home patients with dementia. Despite modest effectiveness and considerable side effects, psychotropic drugs are frequently prescribed for these neuropsychiatric symptoms. This raises questions whether psychotropic drugs are appropriately prescribed. The aim of the PROPER (PRescription Optimization of Psychotropic drugs in Elderly nuRsing home patients with dementia) II study is to investigate the efficacy of an intervention for improving the appropriateness of psychotropic drug prescription in nursing home patients with dementia.

Methods/design: The PROPER II study is a multi-center cluster randomized controlled, pragmatic trial using parallel groups. It has a duration of eighteen months and four six-monthly assessments. Six nursing homes will participate in the intervention and six will continue care as usual. The nursing homes will be located throughout the Netherlands, each participating with two dementia special care units with an average of fifteen patients per unit, resulting in 360 patients. The intervention consists of a structured and repeated multidisciplinary medication review supported by education and continuous evaluation. It is conducted by pharmacists, physicians, and nurses and consists of three components: 1) preparation and education, 2) conduct, and 3) evaluation/guidance. The primary outcome is the proportion of patients with appropriate psychotropic drug use. Secondary outcomes are the overall frequency of psychotropic drug use, neuropsychiatric symptoms, quality of life, activities of daily living, psychotropic drug side effects and adverse events (including cognition, comorbidity, and mortality). Besides, a process analysis on the intervention will be carried out.
\end{abstract}

Discussion: This study is expected to improve the appropriateness of psychotropic drug prescription for neuropsychiatric symptoms in nursing home patients with dementia by introducing a structured and repeated multidisciplinary medication review supported by education and continuous evaluation.

Trial registration: Netherlands Trial Registry (NTR): NTR3569.

Keywords: Dementia, Psychotropic drugs, Nursing homes, Medication safety, Clinical trial

\section{Background}

Neuropsychiatric symptoms (NPS) are highly prevalent in and burdensome for nursing home patients with dementia. Studies show prevalence rates of clinically relevant NPS of over 70\% [1,2], and a cumulative two-year prevalence of even 97\% [3]. NPS comprise a wide range

\footnotetext{
* Correspondence: claudia.smeets@radboudumc.nl

'Department of Primary and Community Care, Centre for Family Medicine, Geriatric Care and Public Health, Radboud university medical center, Code 117 ELG, P.O. Box 9101, 6500, HB Nijmegen, the Netherlands Full list of author information is available at the end of the article
}

of heterogeneous symptoms including delusions, hallucinations, agitation/aggression, depression, apathy, euphoria, anxiety, disinhibition, irritability, and aberrant motor behavior, which are frequently treated with psychotropic drugs. It is known that the efficacy of psychotropic drugs is limited and that their use is associated with considerable side effects such as extrapyramidal symptoms, somnolence, and increased risk for stroke, pneumonia, and mortality [4-7].

Nevertheless, the prevalence of psychotropic drug use (PDU) among nursing home patients with dementia is 
high with rates ranging from 48 to $66 \%$ [8-10]. Moreover, there is a risk for long-term use of psychotropic drugs whereas prescription for only a short period of time is recommended $[4,11]$. For instance, $74 \%$ of the nursing home patients with dementia use antipsychotics, anxiolytics, hypnotics, or sedatives for $83 \%$ of the duration of their stay [12], and $31 \%$ continue the use of antipsychotics, antidepressants, anxiolytics, hypnotics, anticonvulsants, or anti-dementia drugs throughout a 2-year period [9]. The contradiction of widely prescribed psychotropic drugs despite side effects and limited evidence for (long-term) effectiveness, suggests that psychotropic drugs may be prescribed inappropriately.

Systematic reviews on the effect of education, the involvement of pharmacists, and/or a multidisciplinary team show that these interventions may improve drug prescription in the elderly [13] or in nursing homes specifically $[14,15]$. For instance, improvements of about $30 \%$ in the prescription of drugs in nursing home residents [16,17], and discontinuation or dose reduction of antipsychotics in $61 \%$ of patients with dementia [18] have been found. Since the above-mentioned systematic reviews also include high quality studies not showing an effect, the authors suggest to focus in future studies on for example combining methods, multidisciplinary cooperation and direct communication between pharmacist, physician, and nurse, ways to improve the intervention, continuous education, and explicit procedures and routines for medication review. This encouraged us to develop an intervention integrating these elements into a new method of medication review. This medication review will be conducted face-to-face by a multidisciplinary team including not only the physician and pharmacist but also a member of nursing staff. Further, it will be supported by education on practical, organizational, and medical aspects, continuous evaluation, and will be repeated every six months. It is expected that the education and continuous evaluation offered to all participants gives each of them additional knowledge and structure for proper medication review with a specific emphasis on psychotropic drugs. Furthermore, the participation of nurses, through their daily observations representing the patient, and the face-to-face setting is expected to improve the quality of the review.

The PROPER II study (PRescription Optimization of Psychotropic drugs in Elderly nuRsing home patients with dementia) aims to study the effect of a structured and repeated multidisciplinary medication review supported by education and continuous evaluation on the appropriateness of PDU for treatment of NPS in nursing home patients with dementia. Secondary objectives are to investigate NPS, quality of life, activities of daily living, side effects and adverse events (including cognition, hospitalizations, and mortality).

\section{Methods/design}

\section{Design and eligibility}

The study is a multi-center, cluster randomized controlled, pragmatic trial using parallel groups, with a duration of eighteen months, and four six-monthly assessments. Six nursing homes will participate in the intervention and six will continue care as usual. Randomization will be conducted on the level of nursing homes to prevent contamination bias within the nursing home. The nursing homes will be located throughout the Netherlands, and each will participate with two dementia special care units (DSCUs). In the Netherlands, dementia patients usually reside on DSCUs, and medical care including prescription of psychotropic drugs is provided by an elderly care physician employed by the nursing home [19]. In an investigation preceding the PROPER II study, the observational PROPER I study, the same twelve nursing homes will participate. Nursing homes will be selected based upon their responses on a questionnaire regarding the proportion of patients using psychotropic drugs per individual DSCU. In order to maximize variation in the use of psychotropic drugs in the PROPER II study, those nursing homes, more specifically, those DSCUs with either high or low rates, will be approached for participation. Ideally, six nursing homes with high PDU, and six with low PDU will be included. Since the sample size needed for PROPER II (see below) is lower than for the PROPER I study [20], two DSCUs from each participating nursing home will be randomly included in the current study.

In total, 360 patients with a chart diagnosis of dementia will be included, i.e. on average fifteen patients of each of two DSCUs of twelve nursing homes. From DSCUs with more than fifteen patients, a random selection of fifteen patients will be included, regardless of their PDU. For DSCUs with less than fifteen patients, additional DSCUs will participate to retrieve the warranted number of patients per nursing home. Patients who die or are discharged from the DSCU, will be replaced during the study period. Physicians and nurses who are directly involved in the medical treatment and care for the patients will collect the patient data.

This study is a collaboration between the sections for elderly care medicine of three Dutch university Medical Centers and the Dutch Institute for Rational Use of Medicine [21], and is supported by the Dutch association for residential and home care organizations (ActiZ), and the Dutch Health Care Inspectorate.

\section{Intervention}

The intervention consists of a structured and repeated multidisciplinary medication review supported by education and continuous evaluation. It consists of three components: 1) preparation and education, followed by a 
cycle of 2) conduct and 3) evaluation/guidance (Figure 1). A local project coordinator will be assigned to ensure appropriate planning and organization of these components. The first component takes place within one month after the baseline assessment of the trial; the second occurs within one month after the first component, or within one month after the evaluation/guidance meeting of the third component; the third component takes place within one month after the six- and twelve-month trial-assessments.

\section{Component 1: preparation and education}

The first component includes all preparations prior to the actual conduct of the medication review. The major part consists of an educational session. The education includes both the practical and organizational aspects of the medication review, as well as training about the efficacy and side effects of psychotropic drugs. It will be provided locally at each intervention nursing home and is to be attended by physicians, pharmacists, and nurses. The content is based upon the Guideline for problem behavior of the Dutch Association of Elderly Care Physicians and Social Geriatricians (Verenso) [22], and the Multidisciplinary guideline Polypharmacy in the elderly [23] including the STRIP method and Dutch versions of the START and STOPP tools [24]. The STRIP is the Systematic Tool to Reduce Inappropriate Prescribing and is a guidance for conducting structured medication reviews, the START is the Screening Tool to Alert doctors to Right Treatment, and the STOPP is the Screening Tool of Older Person's potentially inappropriate Prescriptions. This education will be provided by the Dutch Institute for Rational Use of Medicine (IVM), which is specialized in the distribution of information and solutions for the proper, safe, affordable and effective use of medicine. The education is developed by the IVM in cooperation with the authors. Next to the education, this

\section{Component 1: Preparation and education}

- Education on practical and organizational aspects of medication review, as well as on efficacy and side effects of psychotropic drugs

- Planning of responsibilities and timelines

- Definition of sources of information to be used during medication reviews

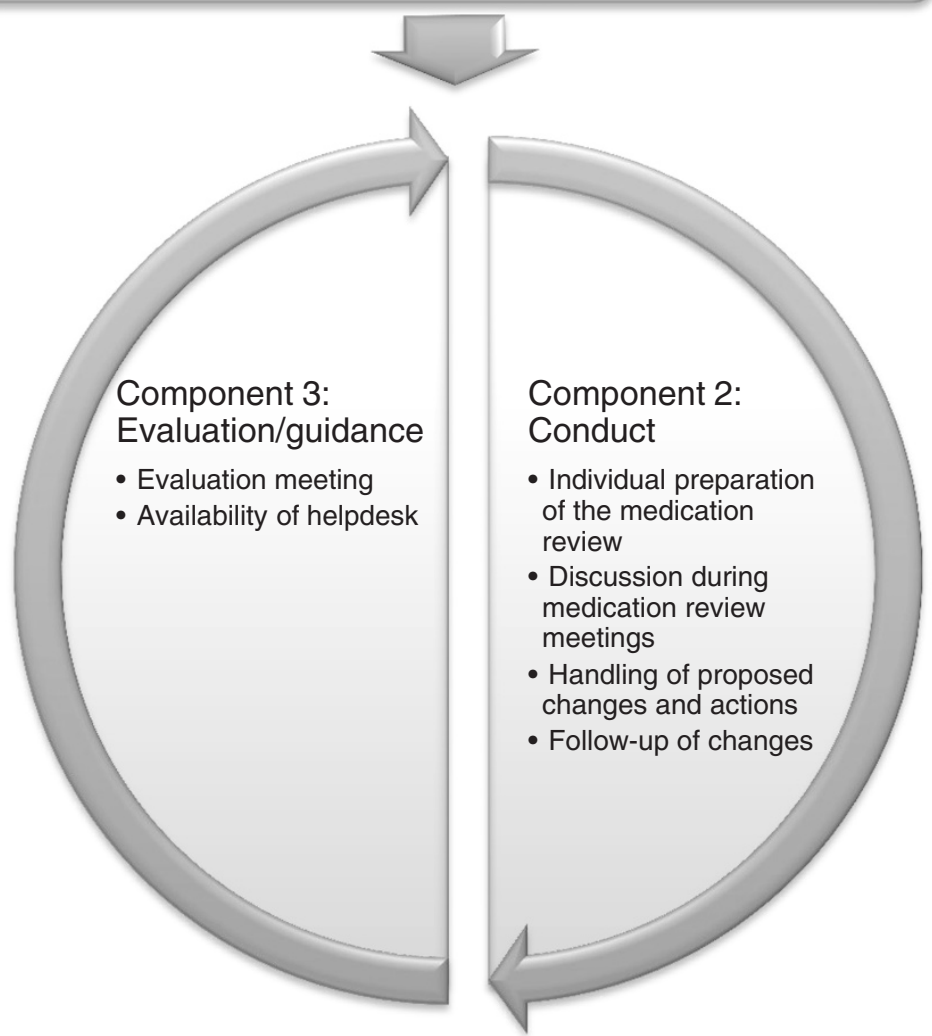

Figure 1 Intervention of the structured and repeated multidisciplinary medication review supported by education and continuous evaluation, consisting of three components. 
component comprises assigning responsibilities of the physicians, pharmacists, and nurses involved, timelines to be followed, and defining those sources of information that each of the participants will use for the medication review.

\section{Component 2: conduct}

The second component includes the actual conduct of the medication review and follow-up per individual patient. The structure is largely based on the STRIP [23]. The conduct of medication reviews per individual patient is a process of preparation, discussion on medication during the medication reviews, execution of the actions proposed, and evaluation of changes. The medication review will be conducted by a team consisting of an (elderly care) physician, pharmacist, and a nurse (assistant). Each of the participants will prepare the medication review. The physician is responsible for collecting medical data of the patient relevant for the discussion, such as type of dementia, comorbidity, and contraindications. The pharmacist is accountable for the actual medication list, knowledge on drug-drug interactions, and dosages. Whereas the STRIP involves the patient in the preparation of the medication review, the patient is in this study represented by the nurse. The nurse is therefore responsible for collecting information about the patient's current behavior and potential PDU-related side effects and adverse events by means of completing a checklist per patient prior to the medication review. The medication review focuses on the appropriate prescription of psychotropic drugs for NPS, but also includes review of other drugs. During the discussion, the team determines whether (psychotropic) drugs must be additionally prescribed, tapered, discontinued, dose-adjusted, or replaced, and whether other actions are needed. These encompass additional diagnostics such as blood checks or electrocardiography, further observations of side effects and adverse events or NPS, referral to a psychologist or to a medical specialist, and use of psychosocial interventions by nursing staff in behavioral management. Proposed changes and actions will be registered and implemented after obtaining consent from the patient's representative. (Non)compliance to the proposed actions is also registered. Further, changes in medication will be followed-up continuously by the physician and nurse.

\section{Component 3: evaluation/guidance}

Evaluation meetings regarding the conduct of the medication reviews will be organized to provide continous evaluation by guiding and counseling in the process of medication review. These meetings will be provided by the IVM and are to be attended by physician, pharmacist and nurse. Moreover, a help desk provided by the IVM is available for questions.

\section{Outcomes}

\section{Primary outcome}

The primary outcome is the appropriateness of PDU defined as the proportion of patients with appropriate PDU. Assessment of appropriateness in this study is limited to antiepileptics, antipsychotics, anxiolytics, hypnotics/sedatives, antidepressants, and anti-dementia drugs prescribed for treatment of NPS in dementia, for sleep disturbances, and for delirium. Based on the Medication Appropriateness Index [25], a scale will be developed specifically for those psychotropic drugs used for treatment of NPS in nursing homes. Information will be included from the Guideline for problem behavior of the Dutch Association of Elderly Care Physicians and Social Geriatricians (Verenso) [22], the Guideline for diagnostics and medical treatment of dementia of the Dutch Geriatrics Society [26], the drug database of the Royal Dutch Pharmacists Association [27], and the 'Farmacotherapeutisch Kompas' [28], a reference of drugs available in the Netherlands published by the Dutch Health Care Insurance Board (CVZ).

\section{Secondary outcomes}

Secondary outcomes are the overall frequency of PDU, NPS, quality of life, activities of daily living, psychotropic drug side effects and adverse events (including cognition, hospitalizations, and mortality).

The overall frequency of PDU will be collected from the patients' medical files or from (prints of) the electronic pharmacist information system and categorized using the Anatomical Therapeutic Chemical (ATC) classification [29] into the following therapeutic subgroups: antiepileptics (N03A), antipsychotics (N05A), anxiolytics (N05B), hypnotics and sedatives (N05C), antidepressants (N06A), and anti-dementia drugs (N06D).

NPS will be assessed using the Neuropsychiatric Inventory - Questionnaire (NPI-Q), the Cohen-Mansfield Agitation Inventory (CMAI), the Nijmegen ObserverRated Depression scale (NORD), and the Minimum Data Set Depression Rating Scale (MDS-DRS). The NPI-Q [30] is a brief version of the Neuropsychiatric Inventory, which was developed for measuring NPS in dementia [31]. The NPI-Q consists of twelve items on NPS, each scored for occurrence (yes/no format), severity (three-point Likert scale), and associated caregiver distress of NPS (six-point Likert scale). A validated Dutch version will be used [32]. The CMAI is a questionnaire on 29 agitated behaviors reflecting physical aggression, physically nonaggressive behavior, and verbally agitated behavior. All items regard frequency of behavior using a seven-point Likert scale [33]. The (construct) validity of the Dutch version [34,35] and reliability [36] have been extensively studied. The NORD is a recently developed and promising Dutch questionnaire on occurrence (yes/no format) of five observable depressive symptoms, for screening of depression in nursing home 
residents with or without dementia [37]. The MDS-DRS is a seven-item observational instrument consisting of seven items on depression derived from the Minimum Data Set of the Resident Assessment Instrument (MDS-RAI) $[38,39]$. Each item is scored for frequency on a three-point scale. The Dutch version of this instrument was studied for validity and reliability and considered suitable for research in nursing homes [40].

Quality of life will be assessed using the Qualidem, a 37-item observational instrument consisting of nine subscales for measuring quality of life, each item is scored for frequency on a four-point scale. It was developed for Dutch nursing home patients with dementia and proven reliable and valid $[41,42]$. In order to allow proper interpretation of the Qualidem scores, the severity of dementia will be assessed using the Global Deterioration Scale, a staging instrument indicating cognitive deterioration in dementia [43]. Additionally, the Revised Index of Social Engagement (RISE) [44] will be assessed. This is an observational instrument with six dichotomous items on social behavior, which is considered to contribute to quality of life. The RISE is a revised version of the Index of Social Engagement [45], and is derived from the MDS-RAI [38,46].

Activities of daily living will be assessed using a questionnaire also derived from the MDS-RAI [47], of which validity and reliability of the Dutch version were established [40]. This scale has been adapted for the Dutch nursing home situation and scoring was simplified, resulting in a scale of twelve items to be scored on a four-point scale for level of independence, and a thirteenth item regarding change compared with the previous month (Joke Smallenburg, personal communication 2011).

Psychotropic drug side effects and adverse events will be assessed by symptoms and disorders related to PDU, cognition, hospitalizations, and mortality. A scale representing common symptoms and disorders related to PDU will be developed for this study, based upon the Udvalg for kliniske undersogelser side effect rating scale (UKU) [48]. Cognition will be assessed using the Severe Impairment Battery-8 [49], a brief version of the Severe Impairment Battery [50]. It was developed as a brief instrument for patients with severe Alzheimer's disease and is sensitive to change over time. The SIB-8 was translated into Dutch for this study. Hospitalizations will be assessed by the number, indication, and duration as reported by the physicians, and mortality will be derived from the patients' medical files.

All assessments will take place at baseline, six months, twelve months and eighteen months. An overview of the outcomes is shown in Table 1.

\section{Baseline characteristics}

Other characteristics collected at baseline will be: age, sex, duration of nursing home admission, type of dementia as documented in the patients' files, and comorbidity.
Comorbidity will be assessed using a checklist on 25 chronic diseases considered most prevalent in a nursing home population. This checklist is a selection of those International Classification of Primary Care (ICPC) chronic diseases and comorbidities that are most prevalent in general practice [51], and adapted for the PROPER II study.

\section{Process analysis}

Also, a process analysis will be carried out on the actual use of the intervention and the factors determining its implementation, especially regarding facilitators and barriers. In addition, reasons for non-compliance with the intervention and time spent on medication review will be assessed, and the meetings guided by the IVM will be evaluated. Separate checklists for nurses, physicians, pharmacists, as well as for the nursing home's local project coordinator will be used.

\section{Sample size}

Assuming an increase in the proportion of patients with appropriate PDU from $60 \%$ to $80 \%$ in the intervention group and equal randomization to the intervention or control group, a significance level (alpha) of 0.05 , a power of $80 \%$, an average cluster size of fifteen patients per DSCU, and an ICC of 0.05 [52], a sample size of 21 clusters is sufficient to detect a statistically significant difference applying Russ Lenth software [53] and calculation methods according to Twisk [54]. Allowing for a DSCU drop-out of ten percent, in total 23 clusters are needed, resulting in the inclusion of two DSCUs in each of twelve nursing homes.

\section{Statistical analysis}

Multilevel analysis will be applied to study the change in the proportion of patients with appropriate PDU between baseline and the average at six, twelve, and eighteen months on intervention DSCUs and control DSCUs, after correction of relevant covariates, such as baseline PDU and NPS. The use of a multilevel model will be applied for a number of reasons: patient PDU is hypothesized to be dependent on the prescription policy of the physician and thus to be nested within DSCUs, the longitudinal design and cluster randomization, and the replacement of drop-outs.

\section{Ethics approval}

The local Medical Ethics Review Committee 'CMO Regio Arnhem-Nijmegen' rated the study (number 2012/226) and pronounced that the study is in accordance with the applicable rules in the Netherlands concerning the review of research ethics committees and informed consent. Representatives of all selected patients will be approached in writing to inform them about the study and to give them the explicit opportunity to refrain from participation of the patient in the study. The study will be conducted in accordance with the Declaration of Helsinki [55]. 
Table 1 Overview of outcomes, instruments, and assessor at baseline, six, twelve, and eighteen months

\begin{tabular}{lll}
\hline Outcome & Instrument & Assessor \\
\hline Appropriateness of PDU & To be developed & Researcher \\
Frequency of PDU & Generic name and ATC code & Researcher \\
NPS & & Nurse \\
NPS & NPI-Q & Nurse \\
Agitation/aggression & CMAl & Nurse \\
Depression & NORD & Nurse \\
Depression & MDS-DRS & Nurse \\
Quality of life & & Physician \\
Quality of life & Qualidem & Nurse \\
(For interpretation of Qualidem) & GDS & Nurse \\
Social engagement & RISE & Pctivities of daily living \\
Psychotropic drug side effects and adverse events & Instrument derived from MDS-RAl & Physician \\
Symptoms and disorders related to PDU & & Physician/representative \\
Cognition & Instrument derived from UKU \\
Hospitalizations & SIB-8 & Physician \\
Mortality & Number, indication, and duration & Researcher \\
\hline
\end{tabular}

Abbreviations: PDU psychotropic drug use, ATC Anatomical Therapeutic Chemical, NPS neuropsychiatric symptoms, NPI-Q Neuropsychiatric Inventory - Questionnaire, CMAl Cohen-Mansfield Agitation Inventory, NORD Nijmegen Observer-Rated Depression scale, MDS-DRS Minimum Data Set Depression Rating Scale, GDS Global Deterioration Scale, RISE Revised Index of Social Engagement, MDS-RAl: Minimum Data Set Resident Assessment Instrument, UKU Udvalg for kliniske undersogelser side effect rating scale, SIB-8 Severe Impairment Battery-8.

\section{Discussion}

This protocol presents the design of a cluster randomized controlled trial evaluating the effectiveness of a structured and repeated multidisciplinary medication review supported by education and continuous evaluation to improve appropriate prescription of psychotropic drugs for NPS in nursing home patients with dementia.

The strength of this study's intervention is the multidisciplinary three-component approach of involving professionals who are educated to carry out a structured and repeated medication review. By including not only the pharmacist and physician but also the nurse, the multidisciplinary team is expected to bring optimal knowledge from different perspectives. In this setting, not only medical and pharmaceutical expertise is taken into account, but also insight into the patients' NPS, for which the psychotropic drugs are prescribed. Besides, the nurse has close contact with the representative of the patient, which further allows input on wishes regarding treatment or acceptation of NPS for the individual patient to be included in the medication review. Moreover, this study is a broad collaboration between several Dutch parties. Aside from the sections for elderly care medicine of three Dutch university Medical Centers, which have close connections with numerous nursing homes, the Dutch Institute for Rational Use of Medicine, the Dutch association for residential and home care organizations (ActiZ), and the Dutch Health
Care Inspectorate are actively involved in this project. This has not only contributed to the design of the study and structure of the intervention, but will also facilitate the knowledge transfer of the results to daily practice after completion of the study. In case effectiveness of this threecomponent intervention is shown, this medication review method will be used on a broader scale to increase awareness of physicians, pharmacists and nurses of proper psychotropic drug use.

The study may have some limitations. Firstly, the involvement of a pharmacist for medication review is currently starting to become part of usual care, also in the control nursing homes. However, these medication reviews are most likely not introduced in a similar education-based, structured, and multidisciplinary fashion. Secondly, the turn-over of pharmacists, physicians, and/or nurses will affect the knowledge regarding the proposed conduct of the medication reviews, in case new staff did not attend the education sessions. However, due to the pragmatic design, the study will have a large external validity and it is expected that a potential effect is at least not overestimated.

Concluding, in the PROPER II study we target to improve the quality of pharmacological treatment of NPS of nursing home patients with dementia, by implementing a sound intervention of a structured and repeated multidisciplinary medication review supported by education and continuous evaluation. 


\section{Competing interests}

The authors declare that they have no competing interests.

\section{Authors' contributions}

SZ designed the study, DG and MS co-designed, and RK assisted in designing the study. The Dutch Institute for Rational Use of Medicine in cooperation with the authors designed the intervention. CS wrote the paper, and MS, DG, MN, RW, KS, SZ, and RK co-wrote the paper. All authors read and approved the manuscript.

\section{Acknowledgements}

This study was funded by the The Netherlands Organisation for Health Research and Development (ZonMw).

\section{Author details}

${ }^{1}$ Department of Primary and Community Care, Centre for Family Medicine, Geriatric Care and Public Health, Radboud university medical center, Code 117 ELG, P.O. Box 9101, 6500, HB Nijmegen, the Netherlands. ${ }^{2}$ Department of General Practice and Elderly Care Medicine/EMGO + Institute for Health and Care Research, VU Medical Center, P.O Box 7057, 1007, MB Amsterdam, The Netherlands. ${ }^{3}$ Dutch Institute for Rational Use of Medicine, P.O. Box 3089, 3502, GB Utrecht, the Netherlands. ${ }^{4}$ Department of General Practice, University of Groningen, University Medical Center Groningen, HPC FA21, P. O. Box 196, 9700, AD Groningen, the Netherlands.

Received: 17 October 2013 Accepted: 23 October 2013

Published: 1 November 2013

\section{References}

1. Zuidema S, Koopmans R, Verhey F: Prevalence and predictors of neuropsychiatric symptoms in cognitively impaired nursing home patients. J Geriatr Psychiatry Neurol 2007, 20(1):41-49.

2. Seitz D, Purandare N, Conn D: Prevalence of psychiatric disorders among older adults in long-term care homes: a systematic review. Int Psychogeriatr 2010, 22(7):1025-1039.

3. Wetzels RB, Zuidema SU, de Jonghe JF, Verhey FR, Koopmans RT: Course of neuropsychiatric symptoms in residents with dementia in nursing homes over 2-year period. Am J Geriatr Psychiatry 2010, 18(12):1054-1065.

4. Ballard CG, Gauthier S, Cummings JL, Brodaty H, Grossberg GT, Robert P, Lyketsos CG: Management of agitation and aggression associated with Alzheimer disease. Nat Rev Neurol 2009, 5(5):245-255.

5. van lersel MB, Zuidema SU, Koopmans RT, Verhey FR, Olde Rikkert MG: Antipsychotics for behavioural and psychological problems in elderly people with dementia: a systematic review of adverse events. Drugs Aging 2005, 22(10):845-858.

6. Schneider LS, Dagerman K, Insel PS: Efficacy and adverse effects of atypical antipsychotics for dementia: meta-analysis of randomized, placebo-controlled trials. Am J Geriatr Psychiatry 2006, 14(3):191-210.

7. Knol W, van Marum RJ, Jansen PA, Souverein PC, Schobben AF, Egberts AC: Antipsychotic drug use and risk of pneumonia in elderly people. J Am Geriatr Soc 2008, 56(4):661-666.

8. Eggermont LH, de Vries K, Scherder EJ: Psychotropic medication use and cognition in institutionalized older adults with mild to moderate dementia. Int Psychogeriatr 2009, 21(2):286-294.

9. Wetzels RB, Zuidema SU, de Jonghe JF, Verhey FR, Koopmans RT: Prescribing pattern of psychotropic drugs in nursing home residents with dementia. Int Psychogeriatr 2011, 23(8):1249-1259.

10. Nijk RM, Zuidema SU, Koopmans RT: Prevalence and correlates of psychotropic drug use in dutch nursing-home patients with dementia. Int Psychogeriatr 2009, 21(3):485-493.

11. Ballard C, Corbett A, Chitramohan R, Aarsland D: Management of agitation and aggression associated with Alzheimer's disease: controversies and possible solutions. Curr Opin Psychiatry 2009, 22(6):532-540.

12. van Dijk KN, de Vries CS, van den Berg PB, Brouwers JR, den de Jong-van Berg LT: Drug utilisation in dutch nursing homes. Eur J Clin Pharmacol 2000, 55(10):765-771.

13. Kaur S, Mitchell G, Vitetta $L$, Roberts MS: Interventions that can reduce inappropriate prescribing in the elderly: a systematic review. Drugs Aging 2009, 26(12):1013-1028.
14. Verrue CL, Petrovic M, Mehuys E, Remon JP, Vander Stichele R: Pharmacists' interventions for optimization of medication use in nursing homes: a systematic review. Drugs Aging 2009, 26(1):37-49.

15. Forsetlund L, Eike MC, Gjerberg E, Vist GE: Effect of interventions to reduce potentially inappropriate use of drugs in nursing homes: a systematic review of randomised controlled trials. BMC Geriatr 2011, 11:16.

16. Stuijt CC, Franssen EJ, Egberts AC, Hudson SA: Appropriateness of prescribing among elderly patients in a dutch residential home: observational study of outcomes after a pharmacist-led medication review. Drugs Aging 2008, 25(11):947-954.

17. Patterson SM, Hughes CM, Crealey G, Cardwell C, Lapane KL: An evaluation of an adapted U.S. model of pharmaceutical care to improve psychoactive prescribing for nursing home residents in northern ireland (fleetwood northern ireland study). J Am Geriatr Soc 2010, 58(1):44-53.

18. Child A, Clarke A, Fox C, Maidment I: A pharmacy led program to review anti-psychotic prescribing for people with dementia. BMC Psychiatry 2012, 12:155.

19. Schols JM, Crebolder HF, van Weel C: Nursing home and nursing home physician: the dutch experience. J Am Med Dir Assoc 2004 5(3):207-212.

20. van der Spek K, Gerritsen D, Smalbrugge M, Nelissen-Vrancken M, Wetzels R, Smeets C, Zuidema S, Koopmans R: PROPER I: frequency and appropriateness of psychotropic drugs use in nursing home patients and its associations: a study protocol. BMC Psychiatry 2013, 13. http:// www.biomedcentral.com/1471-244X/13/307.

21. Instituut voor verantwoord medicijngebruik. http://www.medicijngebruik.nl/.

22. Smalbrugge M, Boersma F, Kleijer BC, Kok RM, Sival RC, Verburg D, Verheij FRJ, Zuidema SU, NWA: Guideline problem behavior.. 2008.

23. Nederlands huisartsen genootschap - multidisciplinaire richtlijn polyfarmacie bij ouderen. https://www.nhg.org/themas/artikelen/mdr-polyfarmacie-bij-ouderen.

24. Gallagher P, Ryan C, Byrne S, Kennedy J, O'Mahony D: STOPP (screening tool of older Person's prescriptions) and START (screening tool to alert doctors to right treatment). Consensus validation. Int J Clin Pharmacol Ther 2008, 46(2):72-83.

25. Hanlon JT, Schmader KE, Samsa GP, Weinberger M, Uttech KM, Lewis IK, Cohen HJ, Feussner JR: A method for assessing drug therapy appropriateness. J Clin Epidemiol 1992, 45(10):1045-1051.

26. Van Gool WA, Hagemeijer A, Barkhof F, Brouwer KJ, Eefsting JA, Eikelenboom P, Jonker C, Olde Rikkert MGM, Sanders JB, Scheltens PH, Schmand BA, Sival RC, Stam CJ, Steenhoek A, Verhey FRJ, Wind AW, Nederlandse Vereniging voor Klinische Geriatrie: Richtlijn diagnostiek en medicamenteuze behandeling van dementie. Alphen aan den Rijn: Van Zuiden Communications; 2005. http://www.diliguide.nl/document/969/ dementie.html.

27. KNMP kennisbank. http://www.kennisbank.knmp.nl/index.asp.

28. Farmacotherapeutisch Kompas. http://www.fk.cvz.nl/.

29. Nordic council on medicines: guidelines for ATC classification. Oslo: WHO Collaborating Center for Drugs Statistics Methodology; 1990. http://www. who.int/classifications/atcddd/en/.

30. Kaufer Dl, Cummings $J$, Ketchel P, Smith V, MacMillan A, Shelley T, Lopez OL, DeKosky ST: Validation of the NPI-Q, a brief clinical form of the Neuropsychiatric Inventory. J Neuropsychiatry Clin Neurosci 2000, 12(2):233-239.

31. Cummings $J$, Mega M, Gray K, Rosenberg-Thompson S, Carusi DA, Gornbein J: The neuropsychiatric inventory: comprehensive assessment of psychopathology in dementia. Neurology 1994, 44(12):2308-2314.

32. de Jonghe JF, Kat MG, Kalisvaart CJ, Boelaarts L: Neuropsychiatric inventory questionnaire (NPI-Q): a validity study of the dutch form. Tijdschr Gerontol Geriatr 2003, 34(2):74-77.

33. Cohen-Mansfield J, Marx MS, Rosenthal AS: A description of agitation in a nursing home. J Gerontol 1989, 44(3):M77-M84.

34. de Jonghe JF, Kat MG: Factor structure and validity of the dutch version of the cohen-mansfield agitation inventory (CMAI-D). J Am Geriatr Soc 1996, 44(7):888-889.

35. Zuidema SU, de Jonghe JF, Verhey FR, Koopmans RT: Agitation in dutch institutionalized patients with dementia: factor analysis of the dutch version of the cohen-mansfield agitation inventory. Dement Geriatr Cogn Disord 2007, 23(1):35-41.

36. Zuidema SU, Buursema AL, Gerritsen MG, Oosterwal KC, Smits MM, Koopmans RT, de Jonghe JF: Assessing neuropsychiatric symptoms in nursing home patients with dementia: reliability and reliable change 
index of the neuropsychiatric inventory and the cohen-mansfield agitation inventory. Int I Geriatr Psychiatry 2011, 26(2):127-134.

37. Leontjevas R, Gerritsen DL, Vernooij-Dassen MJ, Teerenstra S, Smalbrugge M, Koopmans RT: Nijmegen observer-rated depression scale for detection of depression in nursing home residents. Int J Geriatr Psychiatry 2012, 27(10):1036-1044.

38. Morris JN, Hawes C, Fries BE, Phillips CD, Mor V, Katz S, Murphy K, Drugovich ML, Friedlob AS: Designing the national resident assessment instrument for nursing homes. Gerontologist 1990, 30(3):293-307.

39. Burrows AB, Morris JN, Simon SE, Hirdes JP, Phillips C: Development of a minimum data set-based depression rating scale for use in nursing homes. Age Ageing 2000, 29(2):165-172.

40. Gerritsen D, Ooms M, Steverink N, Frijters D, Bezemer D, Ribbe M: Three new observational scales for use in dutch nursing homes: scales from the resident assessment instrument for activities of daily living, cognition and depression. Tijdschr Gerontol Geriatr 2004, 35(2):55-64.

41. Ettema TP, Droes RM, de Lange J, Mellenbergh GJ, Ribbe MW: QUALIDEM: development and evaluation of a dementia specific quality of life instrument-validation. Int J Geriatr Psychiatry 2007, 22(5):424-430.

42. Ettema TP, Droes RM, de Lange J, Mellenbergh GJ, Ribbe MW: QUALIDEM: development and evaluation of a dementia specific quality of life instrument. Scalability, reliability and internal structure. Int I Geriatr Psychiatry 2007, 22(6):549-556.

43. Reisberg B, Ferris SH, de Leon MJ, Crook T: The global deterioration scale for assessment of primary degenerative dementia. Am J Psychiatry 1982, 139(9):1136-1139.

44. Gerritsen DL, Steverink N, Frijters DH, Hirdes JP, Ooms ME, Ribbe MW: A revised index for social engagement for long-term care. J Gerontol Nurs 2008, 34(4):40-48.

45. Mor V, Branco K, Fleishman J, Hawes C, Phillips C, Morris J, Fries B: The structure of social engagement among nursing home residents. J Gerontol $B$ Psychol Sci Soc Sci 1995, 50(1):P1-P8.

46. Hirdes JP, Fries BE, Morris JN, Steel K, Mor V, Friiters D, LaBine S, Schalm C, Stones MJ, Teare G, et al: Integrated health information systems based on the RAI/MDS series of instruments. Healthc Manage Forum 1999, 12(4):30-40

47. Morris JN, Fries BE, Morris SA: Scaling ADLs within the MDS. J Gerontol A Biol Sci Med Sci 1999, 54(11):M546-M553.

48. Lingjaerde O, Ahlfors UG, Bech P, Dencker SJ, Elgen K: The UKU side effect rating scale. A new comprehensive rating scale for psychotropic drugs and a cross-sectional study of side effects in neuroleptic-treated patients. Acta Psychiatr Scand Suppl 1987, 334:1-100.

49. Schmitt FA, Saxton JA, Xu Y, McRae T, Sun Y, Richardson S, Li H: A brief instrument to assess treatment response in the patient with advanced Alzheimer disease. Alzheimer Dis Assoc Disord 2009, 23(4):377-383.

50. Saxton J, McGonigle-Gibson KL, Swihart AA, Miller VJ, Boller F: Assessment of the severely demented patient: description and validation of a new neuropsychological test battery. Psychol Assess A J Consult Clin Psychol 1990, 2:298-303.

51. van Oostrom SH, Picavet HS, van Gelder BM, Lemmens LC, Hoeymans N, Verheij RA, Schellevis FG, Baan CA: Multimorbidity and comorbidity in the dutch population-data from general practices. Ned Tijdschr Geneeskd 2011, 155:A3193

52. Zuidema SU, de Jonghe JF, Verhey FR, Koopmans RT: Psychotropic drug prescription in nursing home patients with dementia: influence of environmental correlates and staff distress on physicians' prescription behavior. Int Psychogeriatr 2011, 23(10):1632-1639.

53. Java applets for power and sample size. http://homepage.stat.uiowa. edu/ rlenth/Power/.

54. Twisk JWR: Applied multilevel analysis. USA: Cambridge University Press; 2006.

55. WMA declaration of helsinki - ethical principles for medical research involving human subjects. http://www.wma.net/en/30publications/10policies/b3/ index.html.

doi:10.1186/1471-244X-13-280

Cite this article as: Smeets et al:: Improving psychotropic drug prescription in nursing home patients with dementia: design of a cluster randomized controlled trial. BMC Psychiatry 2013 13:280.

\section{Submit your next manuscript to BioMed Central and take full advantage of:}

- Convenient online submission

- Thorough peer review

- No space constraints or color figure charges

- Immediate publication on acceptance

- Inclusion in PubMed, CAS, Scopus and Google Scholar

- Research which is freely available for redistribution

Submit your manuscript at www.biomedcentral.com/submit
() Biomed Central 